Tailoring the microstructure of porous $\mathrm{MgO}$ supports for asymmetric oxygen separation membranes: Optimization of thermoplastic feedstock systems

D.K Ramachandran, F. Clemens, A.J. Glasscock, M. Søgaard, A. Kaiser



PII: S0272-8842(14)00344-7

DOI: http://dx.doi.org/10.1016/j.ceramint.2014.03.017

Reference: CERI8198

To appear in: Ceramics International

Received date: 24 October 2013

Revised date: 13 February 2014

Accepted date: 4 March 2014

Cite this article as: D.K Ramachandran, F. Clemens, A.J. Glasscock, M. Søgaard, A. Kaiser, Tailoring the microstructure of porous $\mathrm{MgO}$ supports for asymmetric oxygen separation membranes: Optimization of thermoplastic feedstock systems, Ceramics International, http://dx.doi.org/10.1016/j.ceramint.2014.03.017

This is a PDF file of an unedited manuscript that has been accepted for publication. As a service to our customers we are providing this early version of the manuscript. The manuscript will undergo copyediting, typesetting, and review of the resulting galley proof before it is published in its final citable form. Please note that during the production process errors may be discovered which could affect the content, and all legal disclaimers that apply to the journal pertain. 


\title{
Tailoring the microstructure of porous Mg0 supports for asymmetric oxygen separation membranes: Optimization of thermoplastic feedstock systems
}

\author{
D.K Ramachandran ${ }^{*}$, F. Clemens², A. J.Glasscock ${ }^{1}$, M. Søgaard ${ }^{1}$, A. Kaiser ${ }^{1}$ \\ ${ }^{1}$ Department of Energy Conversion and Storage, Technical University of Denmark, Frederiksborgvej 399, \\ Building 779, DK-4000 Roskilde, Denmark. \\ 2EMPA, Swiss Federal Laboratories for Materials Science and Technology, Laboratory for High Performance \\ Ceramics, Ueberlandstrasse 129, CH-8600 Dübendorf, Switzerland \\ *Corresponding author, Tel.:+45 4677 4800; fax: +45 4677 5858. E-mail address: dhra@dtu.dk
}

\begin{abstract}
Porous magnesium oxide (Mg0) structures were prepared by thermoplastic processing for use as supports in asymmetric thin film oxygen transport membranes (OTMs). The open porosity, pore size distribution, and resulting gas permeability of the $\mathrm{MgO}$ structures were measured for different feedstock compositions and sintering temperatures. For a composition with 19 vol.\% graphite as a pore-former, sintering temperatures of $1300{ }^{\circ} \mathrm{C}$ and $1400{ }^{\circ} \mathrm{C}$, resulted in support porosities of $36 \%$ and $26 \%$, respectively, and gas permeabilities of $1.4 \times 10^{-16} \mathrm{~m}^{2}$ and $3.1 \times 10^{-16} \mathrm{~m}^{2}$, respectively. Electron microscopy showed that the unexpected increase in gas permeability at temperatures above $1300^{\circ} \mathrm{C}$ was a result of the growth of macro-pores and the opening of bottle-neck pores which resulted in improved pore connectivity. Mercury intrusion porosimetry experiments confirmed an increase in average pore size for samples sintered above $1300{ }^{\circ} \mathrm{C}$, despite a significant decrease in total porosity.

\section{Keywords}

Oxygen transport membranes (OTM), magnesium oxide, thermoplastic feedstock, porous support, microstructure. 


\section{Introduction}

Inorganic oxygen transport membranes (OTM) are of interest for high purity oxygen production and for integration into membrane reactors where high temperature oxygen is required [1]. Pure oxygen is used as a reactant/component in many industrial processes. Combustion of coal using oxygen instead of air removes nitrogen from the flue gas and makes subsequent $\mathrm{CO}_{2}$ capture and sequestration significantly cheaper and more efficient. OTM technology has the potential to improve the process efficiency of a number of systems e.g. syngas production from methane [2-4]. In large-scale industrial syngas production, reactors operate in the temperature range of $700-1050{ }^{\circ} \mathrm{C}$ with a pressure between 2-4 MPa to achieve significant conversion efficiencies, and have very reducing atmospheres containing aggressive gases such as $\mathrm{CO}, \mathrm{CO}_{2}$ and $\mathrm{H}_{2} \mathrm{~S}$. Hence, the ceramic oxygen membrane materials and their auxiliary parts have to be both chemically and structurally stable in order to withstand these harsh conditions for long periods of time. Dense mixed oxide ion- and electron-conducting (MIEC) ceramics based on $\mathrm{Ce}_{0.9} \mathrm{Gd}_{0.1} \mathrm{O}_{1.95-\delta}$ (CGO10) are promising materials for this application and have recently demonstrated high oxygen fluxes of $16 \mathrm{Nml} \mathrm{min}^{-1} \mathrm{~cm}^{-2}$ at $900{ }^{\circ} \mathrm{C}$ under syngas production conditions [5], using a $30 \mu \mathrm{m}$ planar CGO10 membrane supported on a Ni-YSZ support typically used for solid oxide fuel cells [6,7].

There have been significant efforts devoted to fabricating strong and highly-permeable porous support materials for oxygen transport membranes. Both planar and tubular configurations have been investigated along with various methods for fabricating these structures [8-12] in order to achieve high quality components. Thermoplastic processing [13] followed by extrusion is a good method for producing tubular structures, thin walled parts with a thickness below $1 \mathrm{~mm}$ and with close dimensional tolerances can be achieved [14]. Also, it is possible to recycle the feedstock from defective parts and reshape them. Using thermoplastic masses instead of water-based extrusion is advantageous as abrasion of the processing equipment (i.e extruder, chamber, and die head parts) is significantly reduced due to the high polymer content.

A support material for the use in asymmetric oxygen transport membranes should have a low cost, high thermal and chemical stability in the harsh operating environment, and good mechanical properties at elevated temperatures. MgO satisfies these requirements $[15,16]$ and is also non-toxic (unlike previously- 
reported perovskite and ceria-based materials) and is hence considered a good candidate for this application. MgO has relatively high thermal expansion coefficient (TEC) than other potential supports material such as YSZ or alumina[17]. However, the TEC of MgO is closer to the values for perovskites or ceria-based composites and it can be easily integrated with these membrane materials in order to prepare multi-layered structures without failures during processing as a result of expansion mismatches[18].

In addition, other factors relating to the processing, final microstructure, and use of the porous support need to be fulfilled:

a) A total open porosity of $35 \%$ to $40 \%$ after sintering to achieve sufficient gas permeation (at a support thickness of 0.5 to $1 \mathrm{~mm}$ ).

b) For co-sintering of the support and the membrane layer it is important that the support layer has a similar sintering activity to the membrane layer to avoid cracking and defect formation during processing. This can be achieved by tailoring the particle size distribution of the raw ceramic powders.

c) For the final application, a membrane layer and thin catalytic layers (with thicknesses between 10 to $50 \mu \mathrm{m}$ ) need to be deposited on the MgO support by dip-coating, a thermoplastic coating process or infiltration and the support needs to be compatible with these processing steps ( not discussed in detail in this paper).

In this study we describe the preparation and characterization of porous magnesium oxide supports made by thermoplastic processing. The thermoplastic feedstock composition and sintering conditions were varied to investigate their effects on the microstructure and gas permeability of the final porous structure. The processing conditions were further optimized with respect to co-sintering of the MgO with a ceria-based membrane layer.

\section{Experimental}

\subsection{Raw materials}

Mg0 powder (Product \# 12R-0801, Inframat Advanced Materials, USA) was used for the preparation of the porous support along with a graphite powder (V-UF1 99.9, Graphit Kropfmühl AG, Germany) as a pore 
former. The raw $\mathrm{MgO}$ powder was calcined at $1000{ }^{\circ} \mathrm{C}$ to reduce the surface area of the powder. Then the powder was coated with stearic acid dispersed in 1-proponal and mixed for $24 \mathrm{~h}$ using a ball mill before drying at $90^{\circ} \mathrm{C}$. This stearic acid coating reduced the tendency of the fine $\mathrm{MgO}$ raw powder to adsorb water and agglomerate, and improved powder handling (e.g. significantly reduced dust formation during the kneading process). J. Heiber et al. also showed that feedstock properties could be improved using pre-coated powders [19]. Measurements of the particle size distribution (PSD) were undertaken using a particle size analyzer (LS 13320, Beckman coulter, Inc, USA). BET surface areas of the powders were determined using an Autosorb-1 analyzer (Quantachrome Instruments, USA).

\subsection{Feedstock preparation}

In this study, the term "feedstock" refers to the mixture of thermoplastic and ceramic compounds used to prepare warm-pressed planar structures or extruded tubes. Previous studies [13] have shown that thermoplastic compositions designed for injection molding or thermoplastic extrusion can be shaped by warm pressing and give similar microstructures to extruded samples (when the process was carefully controlled). Warm-pressed samples were used here to investigate the microstructural and permeation properties as they are a simple geometry suitable for most of the characterization methods and only a small amount of feedstock was required (unlike extrusion; the proposed method for preparing OTMs in the future).

Feedstocks of MgO were prepared from MgO powder, graphite, a thermoplastic binder (Elvax 250, Du Pont; USA), paraffin wax (Sigma-Aldrich, USA) as a plasticizer, and stearic acid (Sigma-Aldrich, USA) as a dispersant. This system was developed for injection molding by Trunec et al. [20] and later also applied for thermoplastic extrusion. A Plastograph N50 (Brabender, Germany) was used to prepare the thermoplastic feedstocks with an operating temperature of $100{ }^{\circ} \mathrm{C}$. The compositions of the prepared feedstocks are summarized in Table 1.

\section{Table 1 about here}

\subsection{Preparation of porous MgO samples}

The various feedstocks with different composition were warm-pressed into rectangular planar structures $(35 \mathrm{~mm} \times 50 \mathrm{~mm}$ ) with a thickness of $1-2 \mathrm{~mm}$ using a uniaxial press (Model TP600, Fortune). A 
load of $100 \mathrm{kN}$ was applied for $2 \mathrm{~min}$ at $100{ }^{\circ} \mathrm{C}$. After warm pressing the samples were heat treated ("debindered") to remove the organic components and then sintered. These samples were used for thermogravimetry, dilatometry, and porosimetry experiments. The feedstock composition which was considered to have an optimized microstructure (MPG) was also extruded into tubes (14 mm outer diameter and $1 \mathrm{~mm}$ wall thickness) using a Brabender extruder 19/20DN in order to validate that the warm pressing and extrusion of an identical feedstock did indeed produce MgO components with the same properties. The ability to achieve identical properties via different processing will of course depend on the type of binder system, pore former, and plasticizer used.

For the preliminary studies on feedstock development, all samples were warm-pressed and sintered at $1275{ }^{\circ} \mathrm{C}$ for $2 \mathrm{~h}$ with a heating rate of $30^{\circ} \mathrm{C} / \mathrm{h}$. Additionally, the warm-pressed feedstocks were sintered at various temperatures between $1250{ }^{\circ} \mathrm{C}$ and $1400{ }^{\circ} \mathrm{C}$ in order to investigate the influence of the sintering temperature on the final properties.

\subsection{Characterization of the porous MgO samples}

The properties of the different MgO feedstock compositions were characterized by dilatometry, density measurements, mercury intrusion porosimetry, permeability measurements, and electron microscopy, as described in detail in this section.

The geometrical densities of the warm-pressed samples were measured. The packing density of green (as-prepared) samples was calculated from the ratio between the measured green density and the expected green density (calculated by the density and volume fraction of each feedstock component).

The microstructure of the samples was studied using scanning electron microscopy (SEM) (SUPRA35, Carl Zeiss, Germany). The samples for the microstructural characterization were prepared using lap polishing with decreasing coarseness of sandpaper/polishing solution, where the last stage of polishing used $0.25 \mu \mathrm{m}$ diamond paste.

A differential contact dilatometer (DIL $402 \mathrm{CD}$, Netzsch GmbH, Germany) was used to measure the sintering behavior and to characterize the densification behavior of the thermoplastic feedstocks. The

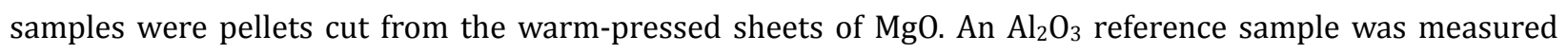


simultaneously with the sample. The heating rate was $3{ }^{\circ} \mathrm{C} \mathrm{min}^{-1}$ to a final temperature of $1450{ }^{\circ} \mathrm{C}$. All experiments were conducted in air with a flow rate of $100 \mathrm{ml} \mathrm{min}^{-1}$.

Porosimetry measurements were conducted using a mercury intrusion porosimeter (AutoPore IV 9510, Micromeritics, Norcross/GA, USA).

Gas permeation measurements were carried out using a system developed in-house. The setup consisted of a gas supply unit, a testing chamber and a unit for measuring the flow of the gas that permeates through the sample. A pressure difference across the sample was created using an electro-pneumatic pressure controller (Tescom, ER3000, USA). The flow of permeated gas was measured using an electronic flow meter (Agilent 5314, USA). The measurements were made with a pressure difference of $200 \mathrm{kPa}$ at room temperature and with nitrogen as the permeate gas. Nitrogen was used for the experiments as it is safe and easy to work with and considered to give similar permeation data to oxygen (the gas of interest for OTM).

MgO supports (MPG) sintered at $1250{ }^{\circ} \mathrm{C}, 1300^{\circ} \mathrm{C}, 1350{ }^{\circ} \mathrm{C}$, and $1400{ }^{\circ} \mathrm{C}$ were used for the gas permeation measurements in order to quantify the gas permeability using the Darcy equation:

$$
j=-k / \mu \cdot \nabla P
$$

where, $\mathrm{k}$ is the permeability $\left(\mathrm{m}^{2}\right), \mathrm{j}$ is the flux $\left(\mathrm{m}^{3} / \mathrm{m}^{2} . \mathrm{s}\right), \mu$ is the viscosity of the gas (Pa.s), and $\nabla \mathrm{P}$ is the pressure gradient ( pressure $(\mathrm{Pa}) /$ sample thickness $(\mathrm{m})$ ).

Fig. 1 shows that the microstructure of $\mathrm{MgO}$ supports prepared by warm pressing is comparable to that of an extruded tube made from the same feedstock MPG (sintering at $1300{ }^{\circ} \mathrm{C}$ for $2 \mathrm{~h}$ ). Additionally, the properties of the warm-pressed and extruded parts were identical with respect to gas permeability $(1.3 \pm 0.1 \times$ $10^{-16} \mathrm{~m}^{2}$ ) and total open porosity $(36 \pm 1 \%)$, validating that the warm pressing method is suitable for preparing samples for studying feedstock compositions for thermoplastic extrusion, as observed previously [13].

Fig. 1 about here 


\section{Result and discussion}

\subsection{Raw materials and feedstock composition}

Table 2 summarizes the results of BET gas adsorption, particle size distribution (PSD), powder density and agglomeration factor (AF) for the raw powders. The agglomeration factor (AF) was calculated from the following equation[21].

$$
\mathrm{AF}=\mathrm{S}_{\mathrm{BET}} \times \mathrm{d} 50 \times \rho / 6
$$

where, $\mathrm{S}_{\mathrm{BET}}, \mathrm{d} 50$ and $\rho$ are specific surface area, median particle size, and powder density respectively.

The uncalcined MgO powder had a very large surface area, $\left(78 \mathrm{~m}^{2} / \mathrm{g}\right.$ as measured by BET), and consisted of extremely fine (nanometric) primary particles that could not be fully de-agglomerated by kneading or dispersion in stearic acid, as indicated by a very high agglomeration factor of 140 . Calcining the MgO powder at $1000{ }^{\circ} \mathrm{C}$ for $10 \mathrm{~h}$ reduced the specific surface area by almost a factor of eight and the agglomeration factor by a factor of 14. Further de-agglomeration of the pre-calcined Mg0 powder was then achieved by coating with stearic acid and ball milling [13].

\section{Table 2 about here}

Another advantage of calcining the MgO powder was a reduction of the particle size distribution; both the D10 and the D90 were significantly reduced compared to the uncalcined powder. The selected graphite pore former had an average particle size (d50 above $11 \mu \mathrm{m}$ ) a factor of $\sim 7$ larger than that of the calcined MgO powder (see Table 2) in order to introduce large stable pores in the microstructure to increase gas permeation in the support.

Fig. 2 shows a ternary compositional diagram for the thermoplastic feedstocks. The white area represents recipes that were able to be processed whereas the compositions in the grey regions could not be prepared due to problems with the kneading, warm pressing/extrusion or thermal treatment process.

Fig. 2 about here 
For compositions with very high solids loading (MgO and graphite) of more than 65 vol.\% the feedstock could not be homogenized due to incomplete wetting of the polymer and a very high viscosity (referred to as the "unmixable region"). At very high polymer contents above 65 vol.\%, especially at high ratios of polymer to ceramic, the $\mathrm{MgO}$ structure deformed or collapsed during the shaping or heat treatment; this region is labeled "form instabilities". In the region in the center of the ternary diagram (where the polymer and graphite content exceeded 65 vol.\%) the prepared feedstocks were form-stable during extrusion but the MgO structures were not mechanically stable after sintering. Hence, only the white area of the compositional diagram, representing successful samples, was investigated in further detail. The data points in this region illustrate the three strategies for systematically studying the feedstock compositions (1) varying the polymer concentration (red data points, samples MP1-5), (2) increasing the pore former concentration with a fixed MgO content (blue data points, samples PG2-3) and (3) increasing the pore former concentration with a fixed polymer content (black data points, samples MG1-4).

\subsection{Influence of polymer content on the porosity}

Feedstocks with different ratios of polymer to ceramic were prepared to investigate the influence of the polymer content on the formation of open porosity after sintering. Table 3 summarizes the compositions and properties of warm-pressed planar structures before organic removal (green state), and after sintering.

\section{Table 3 about here}

As expected, the shrinkage and the porosity of the sintered MgO increased gradually from $15 \%$ to $21 \%$ and from $9 \%$ to $18 \%$, respectively, with increasing polymer content ( $40 \%$ to $60 \%$ ). It is clear that the porosity can be adjusted by simply changing the powder/polymer ratio, which is an advantage of using thermoplastic processing. However, even at the highest polymer content of $60 \mathrm{vol} . \%$ (the limit for producing a stable ceramic structure), the observed porosity of $18 \%$ is considered too low for sufficient gas permeability. Hence, the addition of a pore-former was required to create additional porosity. In Table 3 it can be seen that the packing density of the green warm-pressed samples increased gradually with increasing polymer content, clearly indicating that the flowability of the feedstocks increased. For MP1 with lowest polymer content of $40 \%$ the packing density of the green warm-pressed sample could be increased to values above $90 \%$ by further 
optimization of the pressing parameters (temperature, pressure) but this was not the main purpose of this study.

\subsection{Influence of pore former ( 50 vol.\% ceramic)}

In order to achieve high porosity values, the amount of pore former was gradually increased (replacing the polymer) at constant MgO powder concentration of 50 vol.\%, as shown by the blue line in Fig. 2. Table 4 shows that the porosity could be significantly increased from $13 \%$ to $31 \%$ by the addition of $10 \%$ graphite in the MgO feedstock. It can be seen that feedstock PG3 (with 10\% graphite) had a low packing density in the green state of 0.88 . This indicates that (under the conditions used here for warm pressing), a polymer content of 40 vol.\% is too low to achieve a homogeneous green body without small air inclusions. Hence, for this system, it can be concluded that the lower limit of the polymer content is above $40 \%$ in order to avoid air inclusions in the feedstock and subsequent processing problems.

\section{Table 4 about here}

\subsection{Influence of pore former content on support properties (constant polymer content of 45 vol.\%)}

Table 5 shows the effect of graphite content (0 to 20 vol.\%) on the properties of the sintered MgO (constant polymer content of $45 \mathrm{vol.} \%$, sintered at $1275^{\circ} \mathrm{C}$ ). Comparing the compositions MP2, MG1 and MG2 with $0 \%, 5 \%$ and $10 \%$ graphite, respectively, the porosity increased almost linearly with the addition of graphite. It is worthwhile noting that the pore size distribution of the compositions changed from monomodal to bi-modal at graphite concentrations above 10 vol.\%. Furthermore, the size of the second peak representing the larger pore sizes increased with increasing pore former content.

\section{Table 5 about here}

Also shown in Table 5 are the data for MPG (19 vol.\% graphite) which lie between those for MG3 and MG4 with respect to graphite content and final porosity. This composition was selected for further study as it porosity was within the targeted range $(35-40 \%)$ and it showed the best overall behavior during processing (of the studied samples within the operational window shown in Fig. 2). Also, large quantities of MPG could be easily processed and hence this composition was considered suitable for up-scaling of the process in the future. 
Fig. 3 shows SEM images of polished cross-sections of the MgO supports MP2 and MG1 to MG4. An increase in the absolute porosity and the fraction of larger pores was observed when the amount of pore former was increased from 0 to 20 vol.\% (Fig. 3a to f). The graphite pore former produced the larger, elongated and oriented pores with sizes of several microns. The submicron porosity is from the removal of the polymer; these fine pores were also observed for composition MP2 (Fig. 3a), which contained no graphite.

\section{Fig. 3 about here}

\subsection{Influence of sintering temperature}

In the case where the $\mathrm{MgO}$ support will be co-sintered with a membrane layer, the densification behavior of the support during sintering must closely match that of the membrane to avoid mechanical failures e.g. cracking or delamination. Another challenge is to select a co-sintering temperature where the membrane can be fully densified while keeping sufficient porosity in the support. Hence, the densification behavior of the selected MgO feedstock (MPG) was investigated by dilatometry and compared to that of a CGO membrane sample (64 vol.\% CGO and 36 vol.\% polymer). The resulting densification curves in Fig. 4 show that more than $1300{ }^{\circ} \mathrm{C}$ is required for the membrane to reach a density above $85 \%$ (without an extended time at the sintering temperature). Further sintering experiments on CGO feedstocks showed that an isothermal holding time of about $2 \mathrm{~h}$ at $1300{ }^{\circ} \mathrm{C}$ achieved a density of $95 \%$ of theoretical density, which is considered to be sufficiently dense for the application. Hence, it was necessary to investigate the effect of higher sintering temperatures and the $2 \mathrm{~h}$ holding time on the porosity of the $\mathrm{MgO}$. This was done by sintering warm-pressed samples of MPG at $1250{ }^{\circ} \mathrm{C}, 1300^{\circ} \mathrm{C}, 1350^{\circ} \mathrm{C}$ or $1400^{\circ} \mathrm{C}$ for $2 \mathrm{~h}$ and analyzing the resulting porosity by SEM.

\section{Fig. 4 about here}

Fig. 5 shows the microstructures of the MgO samples sintered at different temperatures. At a sintering temperature of $1250^{\circ} \mathrm{C}$ (Fig. 5a) large elongated pores from the graphite are visible (8.7 - $16.6 \mu \mathrm{m}$ in length and aspect ratios between 1.5 and 4.8). When the sintering temperature was increased these larger pores grew slightly, whereas the MgO matrix (skeleton) densified as the finer pores from the polymer were eliminated (Fig. 5b). 


\section{Fig. 5 about here}

$\mathrm{Hg}$ porosimetry measurements were performed on the same $\mathrm{MgO}$ samples as shown in Fig. 5 to quantify the development of the pore size distribution with sintering temperature. The pore size distributions of the MgO supports shown in Fig. 6 confirm the microstructural observations. For sintering temperatures of $1250{ }^{\circ} \mathrm{C}$ and $1300{ }^{\circ} \mathrm{C}$ bi-modal pore size distributions with two distinct peaks are observed; the first peak with an average size below $0.1 \mu \mathrm{m}$ and the second peak including pores above $0.3 \mu \mathrm{m}$. This second peak is present for all four sintering temperatures. It is obvious that with increasing sintering temperature (from $1250^{\circ} \mathrm{C}$ to $1350^{\circ} \mathrm{C}$ ) the smaller pores are completely eliminated from the $\mathrm{MgO}$ skeleton. As expected from the dilatometry measurements (Fig. 4), the porous $\mathrm{MgO}$ will sinter and densify at these temperatures and therefore the porosity below $0.1 \mu \mathrm{m}$ will disappear. For the pores above $0.2 \mu \mathrm{m}$, the median pore diameter shifts from 0.3 to 0.7 when the final sintering temperature increased from $1250{ }^{\circ} \mathrm{C}$ to $1400{ }^{\circ} \mathrm{C}$. The pore size distributions measured by $\mathrm{Hg}$ intrusion (Fig. 6) is significantly smaller compared to the microstructural observations (Fig. 5) and this discrepancy can be explained by the formation of bottleneck pores (e.g. submicron pores) which connect the larger (micrometer range) pores. In the Hg porosimetry technique the pore size is calculated from the pressure required to push the $\mathrm{Hg}$ through the sample and hence the bottleneck (smallest diameter of the pore) will give the measured pore size. Hence, the average pore size of samples with many bottleneck pores can be underestimated using this technique, which is why it was important also to view the microstructure.

The growth of the pores above $0.2 \mu \mathrm{m}$ can be explained by the Oswald repining process; the bottleneck pore size increased because of the densification of the $\mathrm{MgO}$ skeleton. The total porosity of the MgO samples as measured by Hg porosimetry is plotted as a function of sintering temperature in Fig. 6 . As expected, the total porosity decreased with increasing sintering temperature until the sintering temperature reached $1350{ }^{\circ} \mathrm{C}$. There was no further decrease in porosity observed at $1400{ }^{\circ} \mathrm{C}$. The strong decrease in porosity in the temperature range $1250-1350{ }^{\circ} \mathrm{C}$ was a result of the elimination of the small pores in the $\mathrm{MgO}$ skeleton (as evidenced by the disappearance of the smaller pore size peak in Fig. 6).

\section{Fig. 6 about here}




\subsection{Permeability of the MgO supports}

Gas permeation measurements for the MPG samples were conducted in order to correlate the gas flow through the porous structure with the microstructure developed at different sintering temperatures. The permeability of the supports at $\Delta \mathrm{P}$ of $200 \mathrm{kPa}$ is plotted (left axis) as a function of the sintering temperature in Fig. 7a, along with the porosity of the supports (right axis).

\section{Fig. 7 a, b about here}

The permeability was highest for the sample sintered at the lowest temperature of $1250{ }^{\circ} \mathrm{C}$ (with the bi-modal pore size distribution as shown in Fig. 6) and decreased by a factor of more than 3 for a sintering temperature of $1300^{\circ} \mathrm{C}$. Increasing the sintering temperature further to $1350{ }^{\circ} \mathrm{C}$ and $1400{ }^{\circ} \mathrm{C}$ did not further decrease the permeability as could be expected from the lower total porosity values. In fact the permeability of the sample sintered at $1400{ }^{\circ} \mathrm{C}$ was a factor of 2.5 larger than that of the sample sintered at $1350{ }^{\circ} \mathrm{C}$. Considering the microstructural development discussed in the previous section, it is clear that the gas permeation depends not only on the total porosity, but also on the microstructure (pore size, pore shape and interconnectivity of the pores or "tortuosity"). Fig. 7b shows a significant increase in the volume fraction of the larger pores (above $0.5 \mu \mathrm{m}$ ) from below $20 \%$ to almost $90 \%$ when the sintering temperature was increased from 1300 to $1350{ }^{\circ} \mathrm{C}$. Furthermore, the median pore size is more than doubled over the same range. Despite a reduction in the total porosity with increasing temperature, it is clear that the microstructures developed at higher sintering temperatures are beneficial for gas permeation (a higher fraction of large interconnected pores). This is a positive result with respect to co-sintering the MgO supports with CGO membranes; the evaluated sintering temperatures (above $1300^{\circ} \mathrm{C}$ ) required for densifying the CGO are not detrimental for gas permeability and are likely to be beneficial for the mechanical strength of the porous supports.

\section{Conclusion}

Magnesium oxide has a relatively high thermal expansion coefficient compared to other structural ceramics, which makes it a suitable, generic support material for OTM materials such as perovskites or ceriabased materials. Supports with a high total porosity (up to $36 \%$ ) and an average pore size $\sim 0.5 \mu \mathrm{m}$ were 
achieved using a feedstock with 19 vol.\% graphite pore former (particle size $\sim 10 \mu \mathrm{m}$ ) and a sintering temperature of $1300{ }^{\circ} \mathrm{C}$. A significant, unexpected increase in gas permeation through the porous $\mathrm{MgO}$ supports was observed when the sintering temperature was increased from 1300 to $1400{ }^{\circ} \mathrm{C}$, despite a significant decrease in the total porosity. This was explained by the growth and homogenization of the larger pores introduced by the pore former and by improved interconnectivity of the pores (broadening of the pore channels) due to densification. The optimization of the $\mathrm{MgO}$ feedstock resulted in porous supports with suitable microstructures and sintering activity for co-sintering with CGO at temperatures between $1300{ }^{\circ} \mathrm{C}$ and $1400{ }^{\circ} \mathrm{C}$. In the case where these $\mathrm{MgO}$ supports would be used with high-performance membrane layers (delivering oxygen fluxes of $10 \mathrm{ml} \mathrm{min}^{-1} \mathrm{~cm}^{-2}$ or more), these gas permeabilities of 1.4 to $3.1 \times 10^{-16} \mathrm{~m}^{2}$ may limit the performance of the membrane. Therefore further research is being undertaken to enlarge the average pore size of the $\mathrm{MgO}$ supports using alternative pore formers while optimizing the mechanical strength (e.g. using spherical graphite to form more homogenous pores). In addition, extrusion of these thermoplastic feedstocks is being undertaken to produce thin-walled porous MgO tubes onto which catalytic layers and ceria-based membrane layers can be applied by dip-coating and then co-sintered to produce fully functional OTMs.

\section{Acknowledgements}

The authors would like to thank the Danish Council for Independent Research Technology and Production Sciences (FTP) which is part of The Danish Agency for Science, Technology and Innovation (FI) (Project \# 09-072888) for sponsoring the OPTIMAC research work. Pernille Hedemark Nielsen and Marianne Nielsen are thankfully acknowledged for their assistance with the preparation of feedstocks, dilatometry analyses and $\mathrm{Hg}$-porosimetry measurements.

\section{References}

[1] M. Salehi, F. Clemens, E.M. Pfaff, S. Diethelm, C. Leach, T. Graule, et al., A case study of the effect of grain size on the oxygen permeation flux of BSCF disk-shaped membrane fabricated by thermoplastic processing, J. Memb. Sci. 382 (2011) 186-193.

[2] X. Zhu, S. Sun, Y. Cong, W. Yang, Operation of perovskite membrane under vacuum and elevated pressures for high-purity oxygen production, J. Memb. Sci. 345 (2009) 47-52. 
[3] C. Delbos, G. Lebain, N. Richet, C. Bertail, Performances of tubular La0.8Sr0.2Fe0.7Ga0.303- $\delta$ mixed conducting membrane reactor for under pressure methane conversion to syngas, Catal. Today. 156 (2010) 146-152.

[4] P.V. Hendriksen, P.H. Larsen, M. Mogensen, F.W. Poulsen, K. Wiik, Prospects and problems of dense oxygen permeable membranes, Catal. Today. 56 (2000) 283-295.

[5] J. Sunarso, S. Baumann, J.M. Serra, W.A. Meulenberg, S. Liu, Y.S. Lin, et al., Mixed ionic-electronic conducting (MIEC) ceramic-based membranes for oxygen separation, J. Memb. Sci. 320 (2008) 13-41.

[6] a. Kaiser, S. Foghmoes, C. Chatzichristodoulou, M. Søgaard, J. a. Glasscock, H.L. Frandsen, et al., Evaluation of thin film ceria membranes for syngas membrane reactors-Preparation, characterization and testing, J. Memb. Sci. 378 (2011) 51-60.

[7] C. Chatzichristodoulou, M. So gaard, J. Glasscock, A. Kaiser, S.P.V. Foghmoes, P.V. Hendriksen, Oxygen Permeation in Thin, Dense Ce0.9Gd0.101.95- $\delta$ Membranes II. Experimental Determination, J. Electrochem. Soc. 158 (2011) F73.

[8] C. Zhang, Z. Xu, X. Chang, Z. Zhang, W. Jin, Preparation and characterization of mixed-conducting thin tubular membrane, J. Memb. Sci. 299 (2007) 261-267.

[9] D. Bayraktar, F. Clemens, S. Diethelm, T. Graule, J. Van Herle, P. Holtappels, Production and properties of substituted LaFeO3-perovskite tubular membranes for partial oxidation of methane to syngas, J. Eur. Ceram. Soc. 27 (2007) 2455-2461.

[10] a. Chanda, B.X. Huang, J. Malzbender, R.W. Steinbrech, Micro- and macro-indentation behaviour of Ba0.5Sr0.5Co0.8Fe0.203-d perovskite, J. Eur. Ceram. Soc. 31 (2011) 401-408.

[11] D.C. Zhu, X.Y. Xu, S.J. Feng, W. Liu, C.S. Chen, La2NiO4 tubular membrane reactor for conversion of methane to syngas, Catal. Today. 82 (2003) 151-156.

[12] R.Z. Liu, S.R. Wang, B. Huang, C.H. Zhao, J.L. Li, Z.R. Wang, et al., Dip-coating and co-sintering technologies for fabricating tubular solid oxide fuel cells, J. Solid State Electrochem. 13 (2008) 19051911.

[13] M. Salehi, E.M. Pfaff, R.M. Junior, C.P. Bergmann, S. Diethelm, C. Neururer, et al., $\mathrm{Ba} 0.5 \mathrm{Sr} 0.5 \mathrm{Co} 0.8 \mathrm{Fe} 0.203-\delta$ (BSCF) feedstock development and optimization for thermoplastic forming of thin planar and tubular oxygen separation membranes, J. Memb. Sci. 443 (2013) 237-245.

[14] F. Clemens, Thermoplastic Extrusion for Ceramic Bodies, in: F. Händle (Ed.), Extrus. Ceram., Springer Verlag Heidelberg, 2007: pp. 323-345.

[15] M. Lipińska-Chwałek, G. Pećanac, J. Malzbender, Creep behaviour of membrane and substrate materials for oxygen separation units, J. Eur. Ceram. Soc. 33 (2013) 1841-1848.

[16] K. Kwok, H.L. Frandsen, M. Søgaard, P.V. Hendriksen, Stress analysis and fail-safe design of bilayered tubular supported ceramic membranes, J. Memb. Sci. 453 (2014) 253-262.

[17] Y. Shiratori, YSZ-MgO composite electrolyte with adjusted thermal expansion coefficient to other SOFC components, Solid State Ionics. 164 (2003) 27-33.

[18] F. Jtilich, D.- Jtilich, Thermal Expansion of SOFC Materials, 5 (1999) 129-139. 
[19] J. Heiber, F. Clemens, T. Graule, D. Hülsenberg, Thermoplastic Extrusion to Highly-Loaded Thin Green Fibres Containing Pb(Zr,Ti)O3, Adv. Eng. Mater. 7 (2005) 404-408.

[20] M. Trunec, J. Cihlar, Thermal removal of multicomponent binder from ceramic injection mouldings, J. Eur. Ceram. Soc. 22 (2002) 2231-2241.

[21] J. Heiber, F. Clemens, T. Graule, D. Hülsenberg, Influence of Fibre Diameter on the Microstructure and the Piezoelectric Properties of PZT-Fibres, Adv. Sci. Technol. 45 (2006) 2459-2463.

\section{List of Tables}

Table 1. Feedstocks: (MP1-MP5) with various ceramic to polymer ratios and no pore former; (PG2-3) two different pore former contents with a constant ceramic concentration of 50 vol.\%; (MG1-4) different pore former contents with a constant polymer content of $45 \mathrm{vol} . \%$; and (MPG) final feedstock composition that was optimized for up-scaling.

Table 2. BET specific surface area, particle-size distribution (PSD), and the calculated agglomeration factor $(\mathrm{AF})$ for $\mathrm{MgO}$ powder (uncalcined and calcined at $1000^{\circ} \mathrm{C}$ ) and graphite powder.

Table 3. Properties of $\mathrm{MgO}$ support layers with different polymer contents after sintering at $1275{ }^{\circ} \mathrm{C}$ for $2 \mathrm{~h}$ (* measured by Hg porosimetry).

Table 4. Porosity and shrinkage of $\mathrm{MgO}$ supports sintered at $1275^{\circ} \mathrm{C}$ for $2 \mathrm{~h}$ (constant ceramic content of 50 vol.\%) as a function of the graphite to polymer ratio.

Table 5. Porosity and shrinkage of $\mathrm{MgO}$ supports sintered at $1275^{\circ} \mathrm{C}$ for $2 \mathrm{~h}$ (constant polymer content of 45 vol.\%) as a function of the graphite to $\mathrm{MgO}$ ratio.

\section{List of Figures}

Fig. 1 : SEM images of cross-sections of MgO supports (MPG) prepared by extrusion (tubular) and warm pressing (planar), showing comparable microstructures.

Fig. 2 : Ternary compositional diagram for thermoplastic $\mathrm{MgO}$ feedstocks. The data points in the white operational window represent different studies where the following parameters were changed: a) ceramic to polymer ratio (red squares: no graphite pore former), b) graphite to polymer ratio (blue squares, 50 vol.\% ceramic) and pore former to ceramic ratio (black squares, 45 vol.\% polymer). A feedstock with optimized composition was then selected for further studies (circled square). 
Fig. 3 : SEM micrographs of MgO supports with various graphite contents a) no graphite (MP2), b) 5\% graphite (MG1), c) 10\% graphite (MG2), d) 15\% graphite (MG3), e) 20\% graphite (MG4), f) 19\% graphite (MPG). The samples were sintered at $1275^{\circ} \mathrm{C}$ for $2 \mathrm{~h}$.

Fig. 4 : Densification behavior as a function of temperature for an MgO sample (MPG) and a CGO membrane material measured by dilatometry (heating rate: $3^{\circ} \mathrm{C} \mathrm{min}^{-1}$ )

Fig. 5 : SEM micrographs showing the densification and microstructural development of an MgO sample (MPG) at sintering temperatures of a) $\left.\left.1250{ }^{\circ} \mathrm{C}, \mathrm{b}\right) 1300^{\circ} \mathrm{C}, \mathrm{c}\right) 1350{ }^{\circ} \mathrm{C}$ and d) $1400{ }^{\circ} \mathrm{C}(2 \mathrm{~h}$ isothermal holding time).

Fig. 6 : Influence of the sintering temperature $(\mathrm{T})$ on the pore size distribution of $\mathrm{MgO}$ supports $\left(\mathrm{T}=1250{ }^{\circ} \mathrm{C}\right.$, $1300{ }^{\circ} \mathrm{C}, 1350^{\circ} \mathrm{C}$ and $1400^{\circ} \mathrm{C}$ at $2 \mathrm{~h}$ holding time). The corresponding open porosity is denoted by ?.

Fig. 7 : a) Gas permeability and total porosity in $\mathrm{MgO}$ supports and b) volume fraction of pores larger than 0.5 $\mu \mathrm{m}$ and the median pore size of the larger pore size peak as functions of sintering temperature. Porosity and pore size distribution data are taken from the Hg porosimetry measurements.

\section{List of tables:}

Table 1. Feedstocks: (MP1-MP5) with various ceramic to polymer ratios and no pore former; (PG2-3) two different pore former contents with a constant ceramic concentration of $50 \mathrm{vol} \%$; (MG1-4) different pore former contents with a constant polymer content of 45 vol.\%; and (MPG) final feedstock composition that was optimized for up-scaling.

\begin{tabular}{cccc}
\hline Code & $\begin{array}{c}\text { MgO content } \\
\text { Vol.\% }\end{array}$ & $\begin{array}{c}\text { Polymer \& additives } \\
\text { Vol.\% }\end{array}$ & $\begin{array}{c}\text { Graphite } \\
\text { Vol.\% }\end{array}$ \\
\hline \multicolumn{4}{c}{ Various ceramic contents (no pore former) } \\
\hline MP1 & 60 & 40 & - \\
MP2 & 55 & 45 & - \\
MP3 & 50 & 50 & - \\
MP4 & 45 & 55 & - \\
MP5 & 40 & 60 & - \\
\hline \multicolumn{4}{c}{ Various pore former contents, constant Mg0 content 50 vol.\% } \\
\hline MP3 & 50 & 50 & 0 \\
PG2 & 50 & 45 & 5 \\
PG3 & 50 & 40 & 10 \\
\hline \multicolumn{5}{c}{ Various pore former contents, constant polymer content 45 vol.\% } \\
\hline MG1 & 50 & 45 & 5 \\
MG2 & 45 & 45 & 10 \\
MG3 & 40 & 45 & 15 \\
MG4 & 35 & 45 & 20 \\
\hline \multicolumn{4}{c}{ Optimized feedstock composition } \\
\hline MPG & 39 & 42 \\
\hline
\end{tabular}


Table 2. BET specific surface area, particle-size distribution (PSD), and the calculated agglomeration factor (AF) for $\mathrm{MgO}$ powder (uncalcined and calcined at $1000^{\circ} \mathrm{C}$ ) and graphite powder.

\begin{tabular}{lccccc}
\hline \multirow{2}{*}{ Powder } & $\begin{array}{c}\text { Specific surface area } \\
\left(\mathbf{m}^{2} / \mathbf{g}\right)\end{array}$ & $\mathbf{D 1 0}$ & $\mathbf{D 5 0}$ & $\mathbf{D 9 0}$ & Agglomeration \\
\cline { 3 - 5 } & 78.0 & 0.510 & 2.99 & 40.8 & 140.0 \\
\hline Mg0, uncalcined & 10.8 & 0.187 & 1.53 & 6.07 & 10.0 \\
Mg0, $1000^{\circ} \mathrm{C}, 10 \mathrm{~h}$ & 10.5 & 6.53 & 11.3 & 19.9 & $-\cdots$ \\
Graphite & &
\end{tabular}

* PSD measured by laser diffraction after ball milling in ethanol for $24 \mathrm{~h}$ (see section 2.1).

Table 3. Properties of $\mathrm{MgO}$ support layers with different polymer contents after sintering at $1275^{\circ} \mathrm{C}$ for $2 \mathrm{~h}$ (* measured by Hg porosimetry).

\begin{tabular}{lc|cc|ccc}
\hline \multicolumn{2}{c|}{ Composition } & \multicolumn{2}{c|}{ Green state } & \multicolumn{3}{c}{ Sintered state } \\
\hline Code & Polymer & $\begin{array}{c}\text { Density } \\
\left(\mathrm{g} / \mathrm{cm}^{3}\right)\end{array}$ & $\begin{array}{c}\text { Packing } \\
\text { density }\end{array}$ & $\begin{array}{c}\text { Linear } \\
\text { Shrinkage }(\%)\end{array}$ & $\begin{array}{c}\text { *Porosity } \\
(\%)\end{array}$ & $\begin{array}{c}\text { Pore size } \\
(\mu \mathrm{m})\end{array}$ \\
\hline MP1 & 40 & 2.22 & $0.88 \pm 0.02$ & 15.1 & 9.2 & 0.10 \\
MP2 & 45 & 2.20 & $0.92 \pm 0.02$ & 15.7 & 13.5 & 0.07 \\
MP3 & 50 & 2.12 & $0.94 \pm 0.02$ & 15.9 & 13.0 & 0.11 \\
MP4 & 55 & 1.98 & $0.94 \pm 0.02$ & 17.9 & 13.5 & 0.12 \\
MP5 & 60 & 1.90 & $0.96 \pm 0.02$ & 20.8 & 18.2 & 0.15 \\
\hline
\end{tabular}

a Packing density at green state is defined here as the geometrical green density (column 3) compared to the expected green density calculated from the densities and concentrations of each component.

Table 4. Porosity and shrinkage of $\mathrm{MgO}$ supports sintered at $1275^{\circ} \mathrm{C}$ for $2 \mathrm{~h}$ (constant ceramic content of 50 vol.\%) as a function of the graphite to polymer ratio.

\begin{tabular}{ccc|cc|ccc}
\hline \multicolumn{3}{c|}{ Composition } & \multicolumn{2}{c|}{ Green state } & \multicolumn{3}{c}{ Sintered state } \\
\hline Code & Polymer & Graphite & $\begin{array}{c}\text { Density } \\
\left(\mathrm{g} / \mathrm{cm}^{3}\right)\end{array}$ & $\begin{array}{c}\text { Packing } \\
\text { density }\end{array}$ & $\begin{array}{c}\text { Linear } \\
\text { Shrinkage }(\%)\end{array}$ & $\begin{array}{c}\text { Porosity } \\
(\%)\end{array}$ & $\begin{array}{c}\text { Pore size } \\
(\mu \mathrm{m})\end{array}$ \\
\hline MP3 & 50 & 0 & 2.12 & $0.94 \pm 0.02$ & 15.9 & 13.0 & 0.11 \\
PG2 & 45 & 5 & 2.20 & $0.96 \pm 0.02$ & 15.1 & 17.1 & 0.14 \\
PG3 & 40 & 10 & 2.08 & $0.88 \pm 0.02$ & 15.3 & 30.9 & 0.26 \\
\hline
\end{tabular}


Table 5. Porosity and shrinkage of MgO supports sintered at $1275^{\circ} \mathrm{C}$ for $2 \mathrm{~h}$ (constant polymer content of 45 vol.\%) as a function of the graphite to $\mathrm{MgO}$ ratio.

\begin{tabular}{cccc|cc|cccc}
\hline \multicolumn{3}{c|}{ Composition } & \multicolumn{3}{c|}{ Green state } & \multicolumn{3}{c}{ Sintered state } \\
\hline Code & Ceramic & Polymer & Graphite & $\begin{array}{c}\text { Density } \\
\left(\mathrm{g} / \mathrm{cm}^{3}\right)\end{array}$ & $\begin{array}{c}\text { Packing } \\
\text { density }\end{array}$ & $\begin{array}{c}\text { Shinkage } \\
(\%)\end{array}$ & $\begin{array}{c}\text { Porosity } \\
(\%)\end{array}$ & $\begin{array}{c}\text { Pore size peaks* } \\
(\mu \mathrm{m})\end{array}$ \\
\hline MP2 & 55 & 45 & 0 & 2.19 & $0.92 \pm 0.02$ & 15.7 & 14.4 & 0.10 & --- \\
MG1 & 50 & 45 & 5 & 2.21 & $0.94 \pm 0.02$ & 15.1 & 16.0 & 0.15 & --- \\
MG2 & 45 & 45 & 10 & 2.20 & $0.98 \pm 0.02$ & 15.2 & 19.4 & 0.20 & -- \\
MG3 & 40 & 45 & 15 & 2.18 & $0.96 \pm 0.02$ & 14.9 & 32.5 & 0.21 & 0.36 \\
MG4 & 35 & 45 & 20 & 2.03 & $0.96 \pm 0.02$ & 12.1 & 47.5 & 0.08 & 0.42 \\
\hline MPG & $\mathbf{3 9}$ & $\mathbf{4 2}$ & $\mathbf{1 9}$ & $\mathbf{2 . 0 8}$ & $\mathbf{0 . 9 4} \pm \mathbf{0 . 0 2}$ & $\mathbf{1 3 . 4 2}$ & $\mathbf{3 7 . 0}$ & $\mathbf{0 . 0 6}$ & $\mathbf{0 . 4 0}$ \\
\hline
\end{tabular}

*Bi-model pore size distribution (peaks labelled P1 and P2) was observed only when the graphite concentration was more than $10 \%$. 

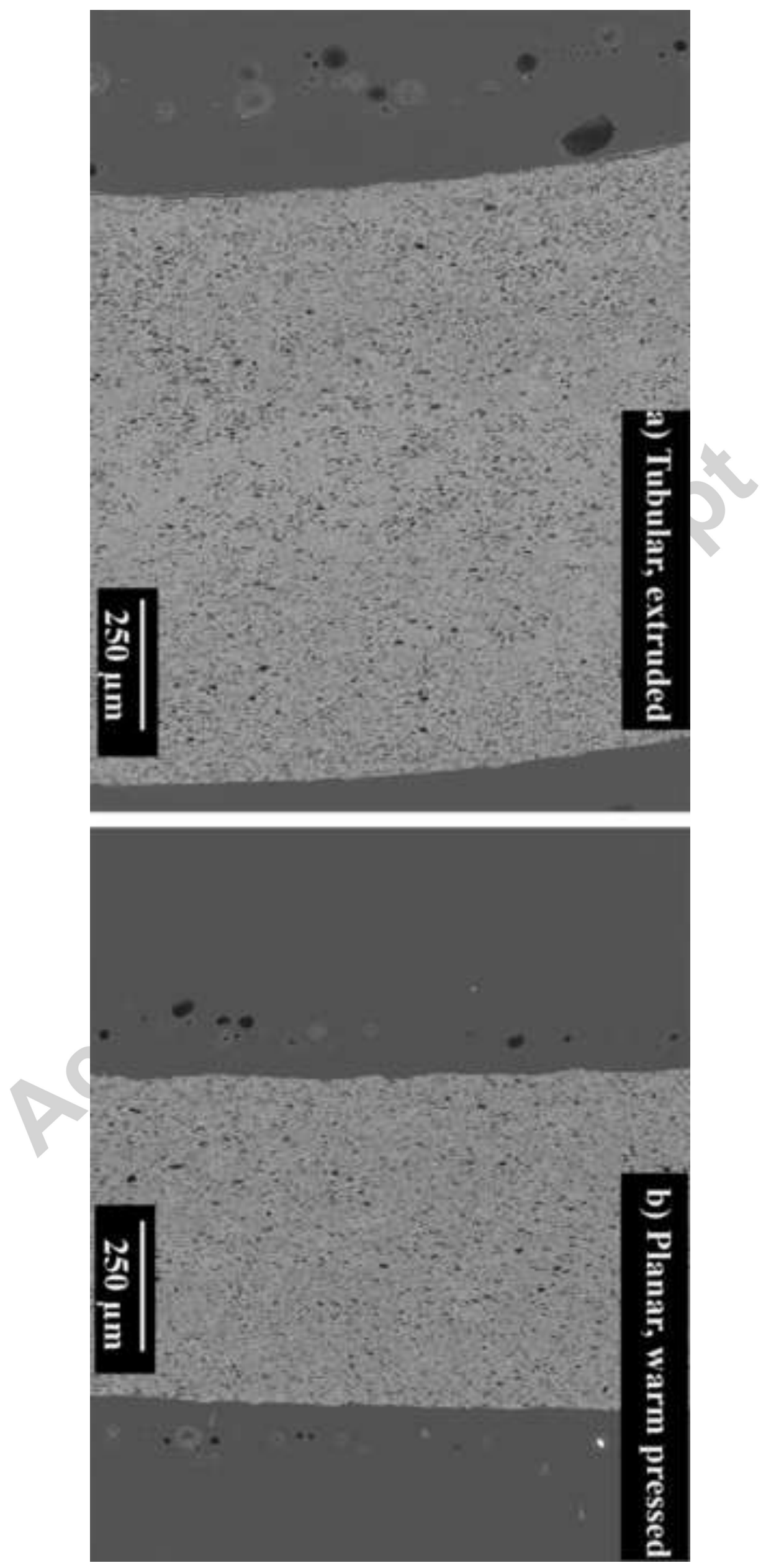


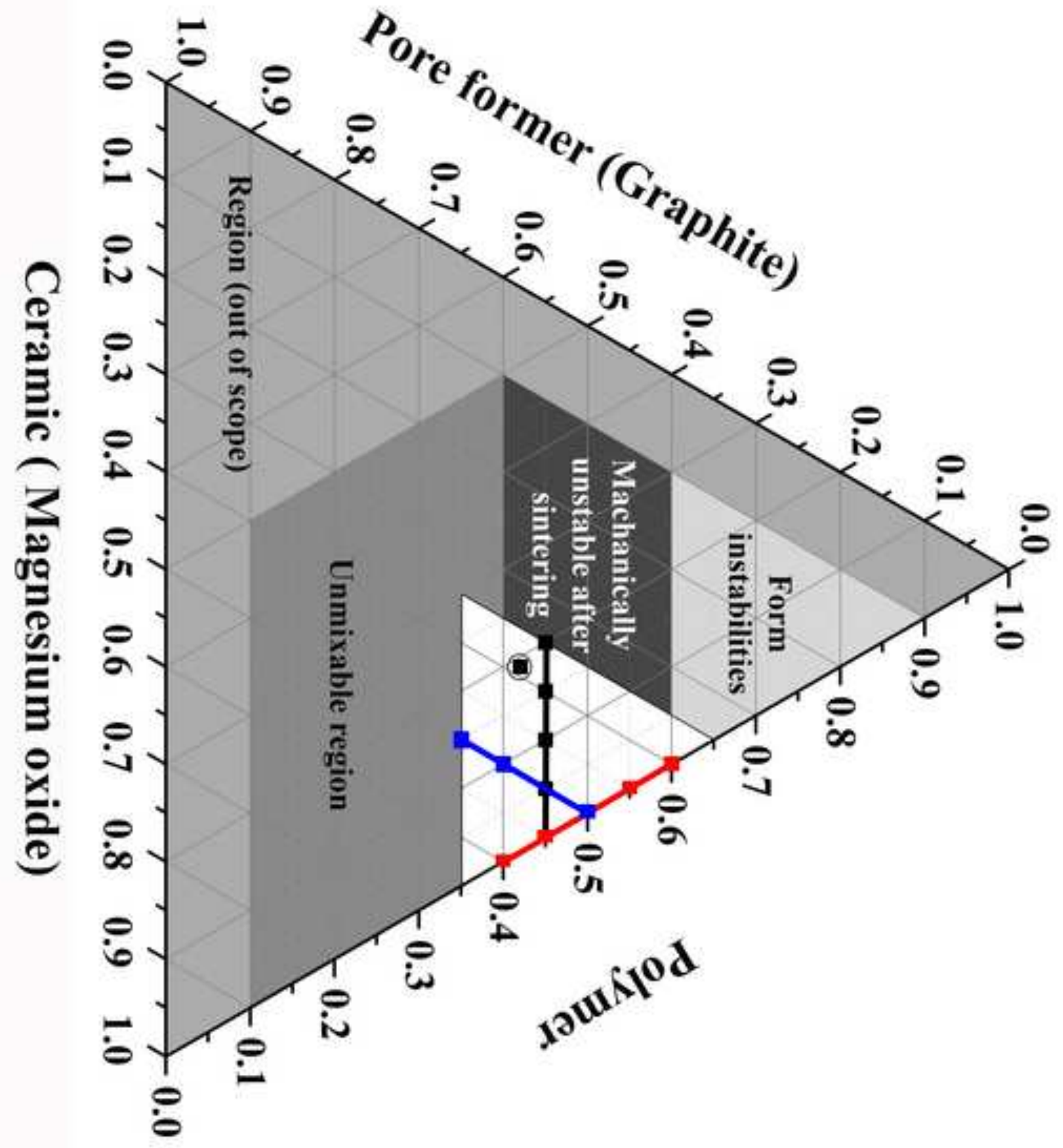







Relative Density

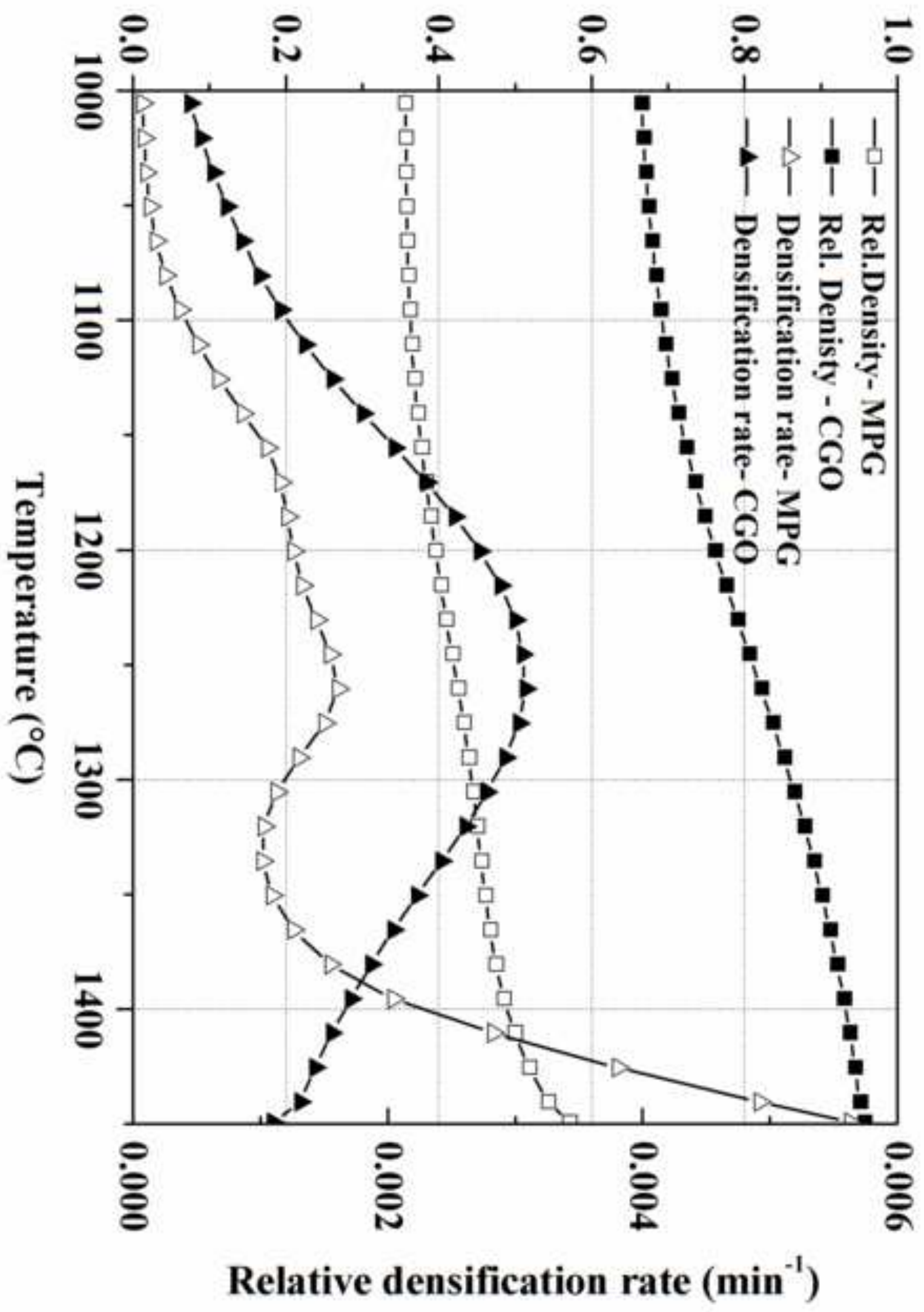



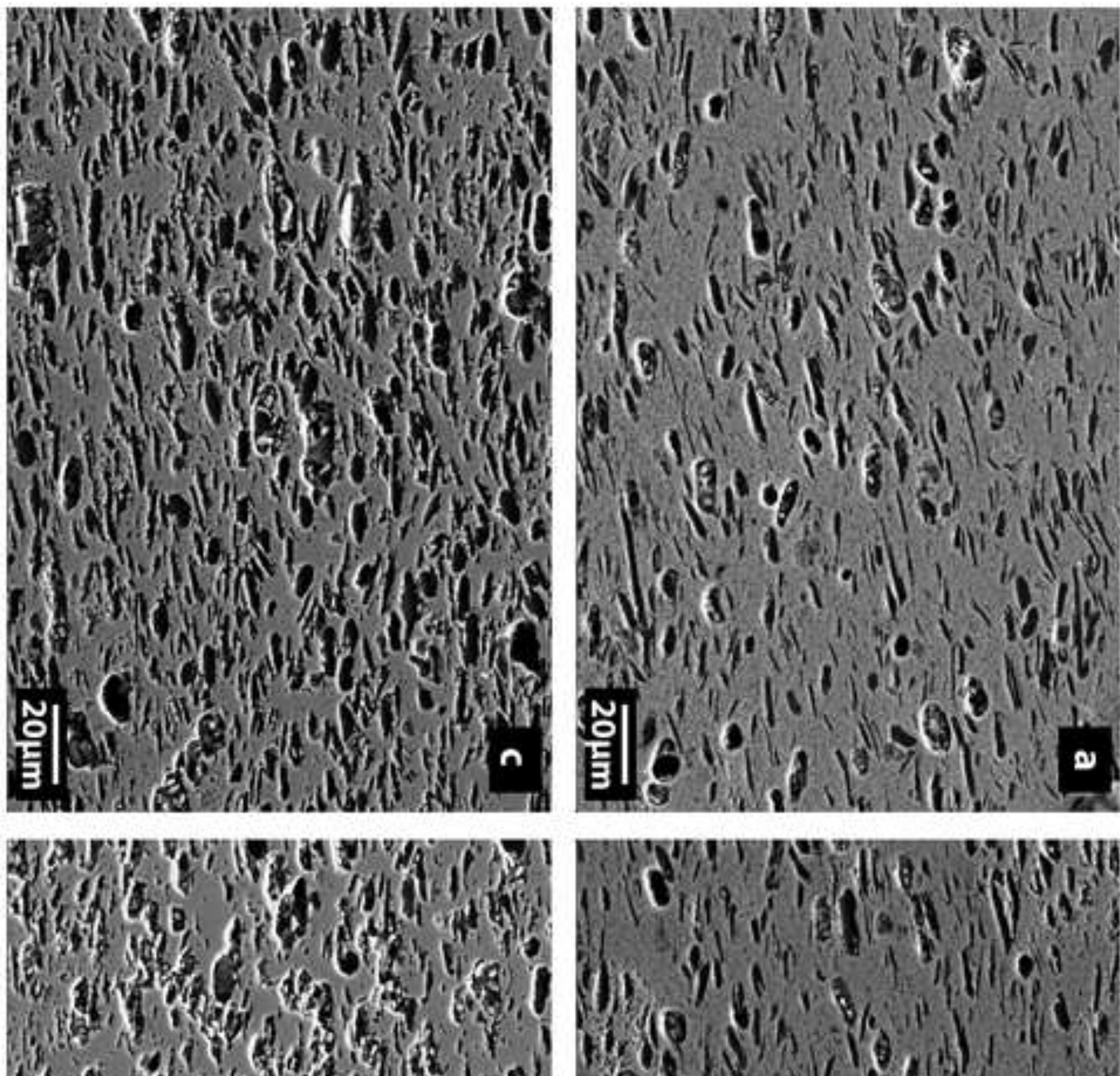

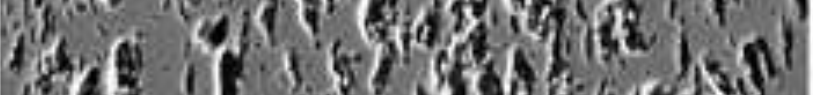
ig 1 a

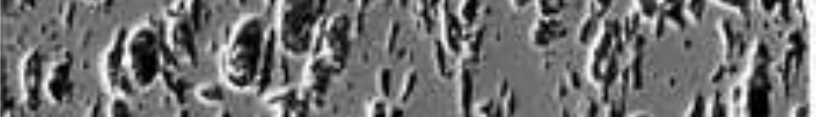


Gof f

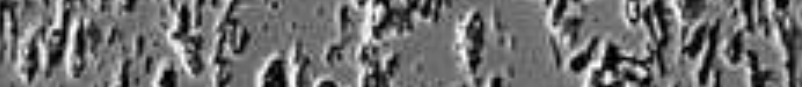



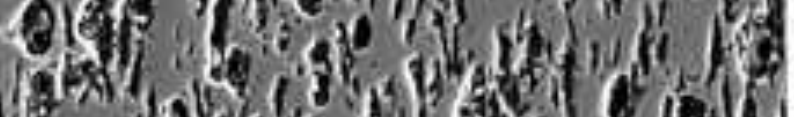

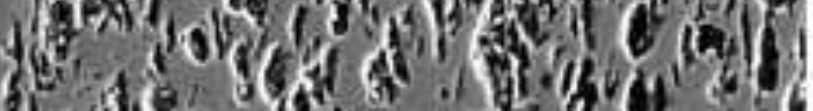
81.

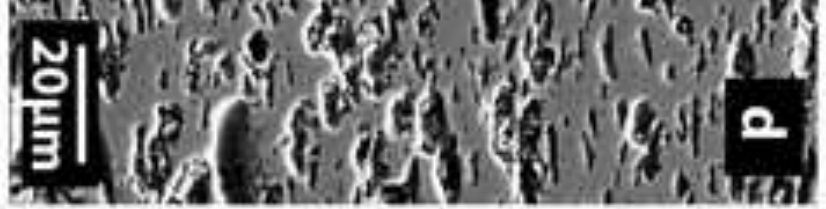

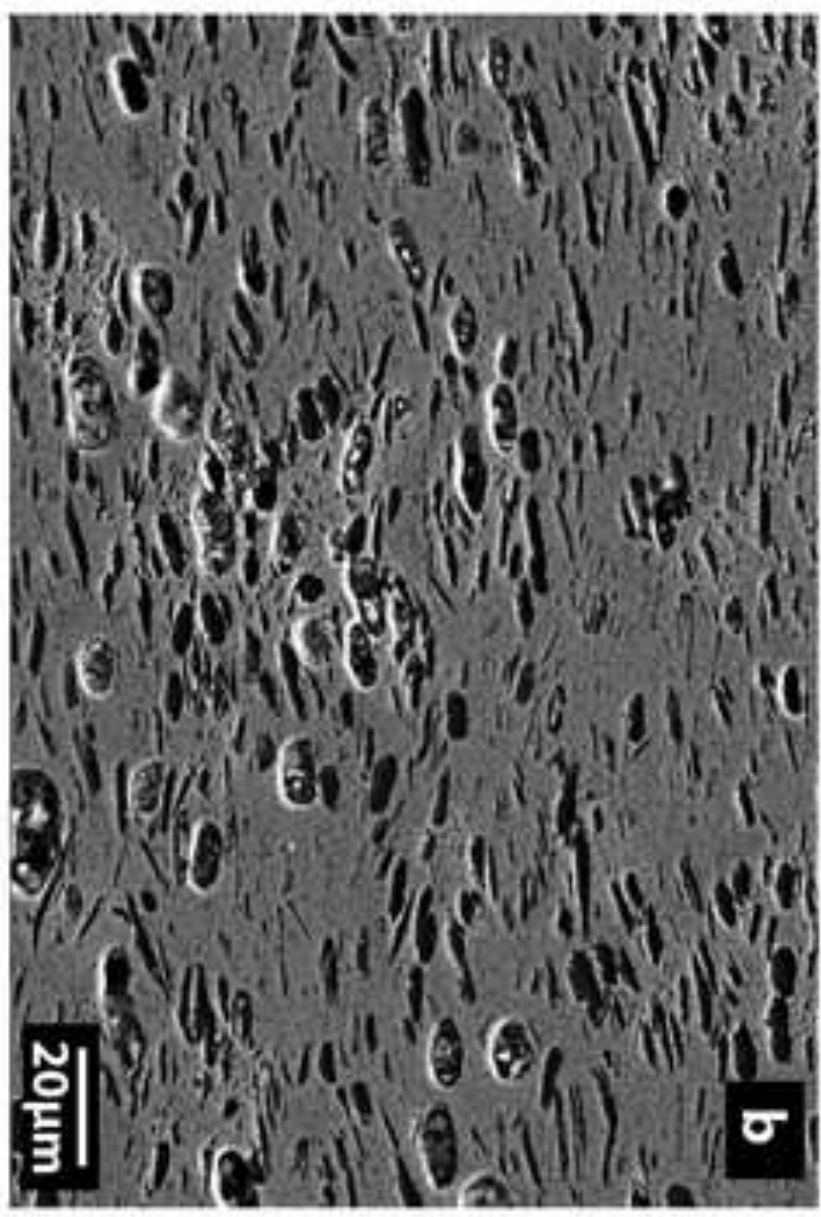




\section{Log differencial intrusion $(\mathrm{mL} / \mathrm{g})$}

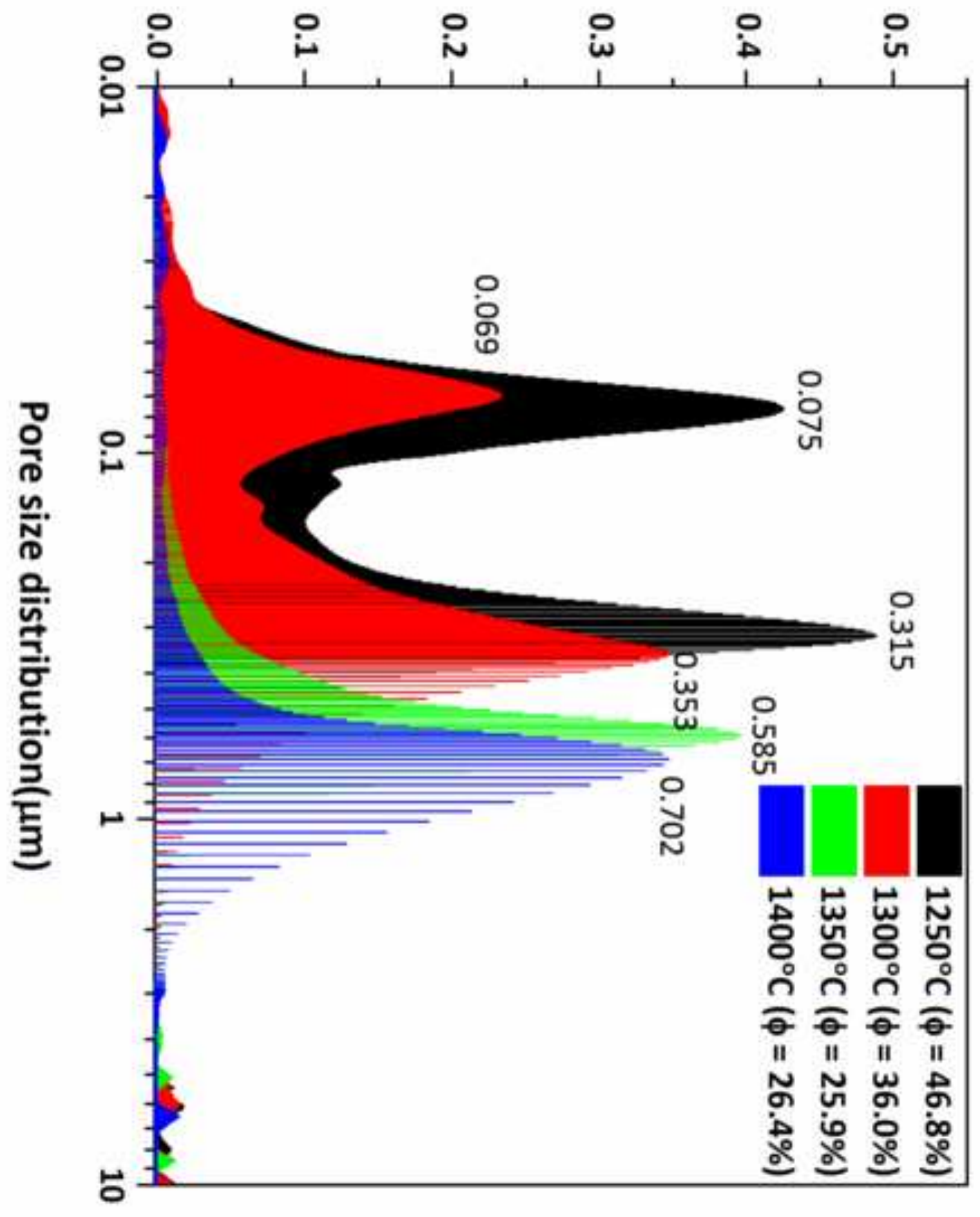




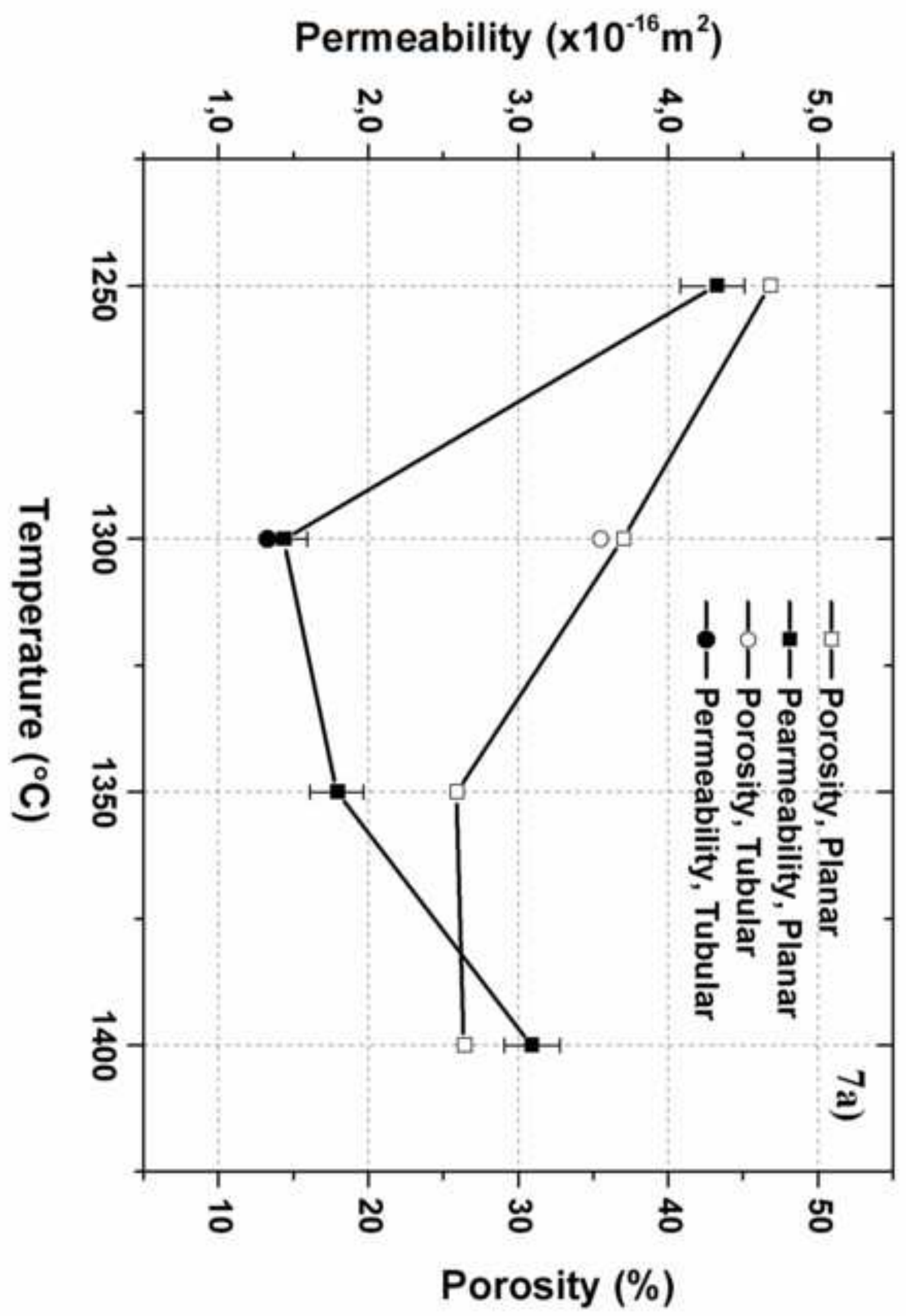




\section{Volume fraction of pores larger than $0.5 \mu \mathrm{m}(\%)$}

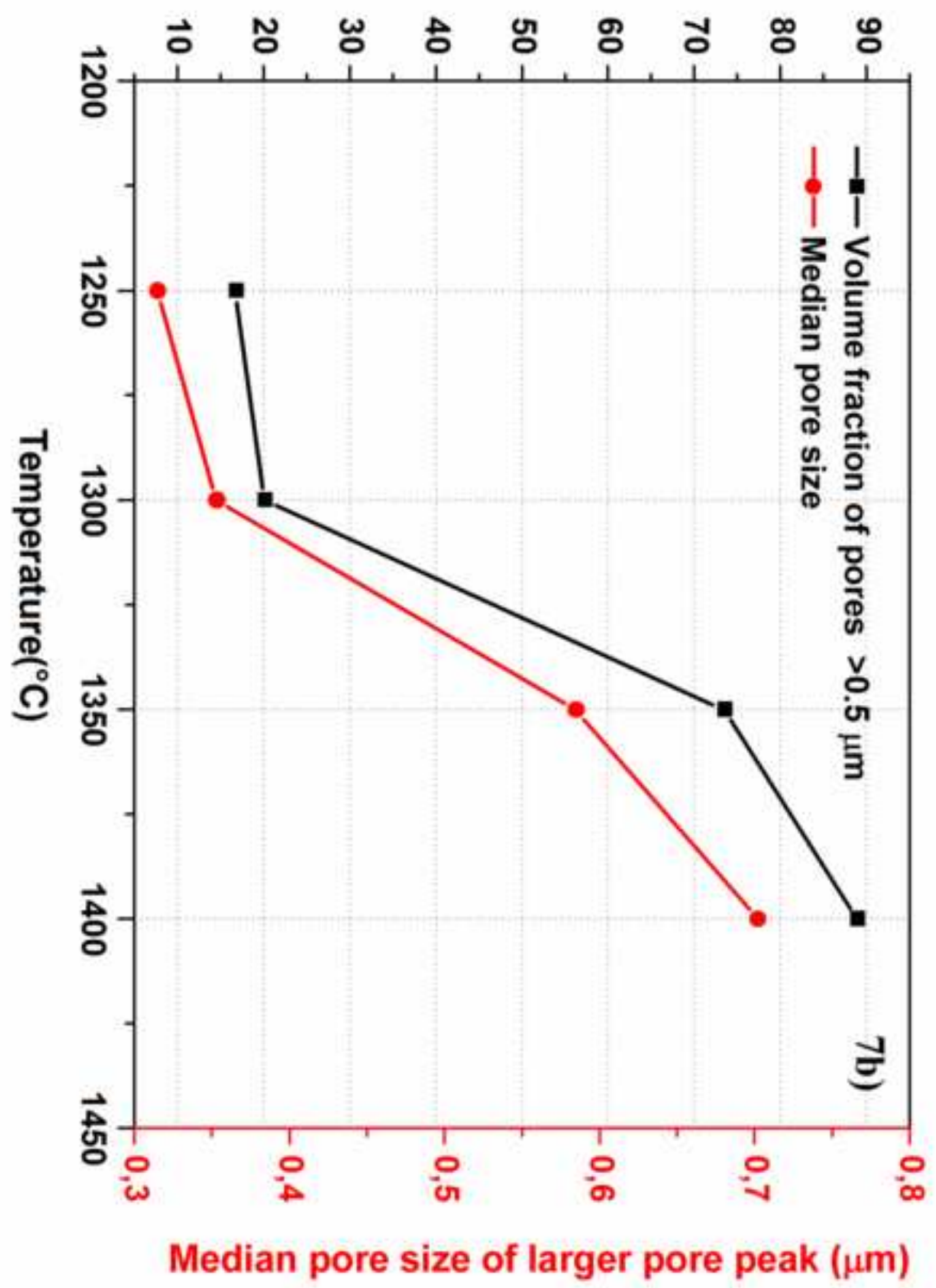

